\title{
Identifikasi Akuifer Air Tanah Menggunakan Metode Geolistrik Tahanan Jenis Konfigurasi Dipol-Dipol Di Masjid Kampus Universitas Sam Ratulangi
}

\author{
Ofvelia Thrisha Gijoha*, As'ari a, Guntur Pasaua \\ aJurusan Fisika, FMIPA, Unsrat, Manado
}

\begin{tabular}{|c|c|}
\hline KATA KUNCI & A B S TR A K \\
\hline $\begin{array}{l}\text { Akuifer } \\
\text { Geolistrik } \\
\text { Konfigurasi Dipol-dipol }\end{array}$ & $\begin{array}{l}\text { Telah dilakukan penelitian akuifer air tanah berdasarkan resistivitas } \\
\text { batuan bawah permukaan. Eksplorasi geofisika menggunakan metode } \\
\text { tahanan jenis konfigurasi dipol-dipol dengan pengkuran dengan } 5 \\
\text { lintasan pengukuran. Data setiap lintasan diolah menggunakan } \\
\text { perangkat lunak RES2DINV, pada setiap lintasan mempunyai } 609 \text { buah } \\
\text { data. Teridentifikasi akuifer air tanah dengan resistivitas } \rho \leq 7,16 \Omega \mathrm{m} \text {. } \\
\text { Akuifer potensial terdapat pada lintasan } 1 \text { di lokasi Masjid bagian Timur } \\
\text { dengan kedalaman } 0-15 \mathrm{~m} \text {, pada lintasan } 3 \text { pada jarak } 40 \mathrm{~m} \text { disebelah } \\
\text { Selatan Masjid dan lintasan } 4 \text { pada jarak } 5 \mathrm{~m} \text { selatan Masjid bagian } \\
\text { Barat dengan kedalaman } 14-18 \mathrm{~m} \text {. }\end{array}$ \\
\hline KEYWORDS & A B S T R A C T \\
\hline $\begin{array}{l}\text { Aquifer } \\
\text { Geoelectric } \\
\text { dipole-dipole configuration }\end{array}$ & $\begin{array}{l}\text { A research on groundwater aquifer has been done according to } \\
\text { subsurface rocks resistivity, the exploration using specific resistivity } \\
\text { method of dipole-dipole configuration by measuring on } 5 \text { lanes. The data } \\
\text { on each lane was processed using RES2DINV software, where each lane } \\
\text { consisted of } 609 \text { data. The identified groundwater aquifer has a } \\
\text { resistivity of } \rho \leq 7,16 \Omega \mathrm{m} \text {. Potential aquifer are on line } 1 \text { which located } \\
\text { eastward from the Mosque with a depth of } 0-15 \mathrm{~m} \text {, on line } 3 \text { with a range } \\
\text { of } 40 \mathrm{~m} \text { southward from the Mosque, and on line } 4 \text { with a range ofnm } \\
\text { westward from the southern side of the Mosque with a depth of } 14-18 \\
\mathrm{~m} \text {. }\end{array}$ \\
\hline
\end{tabular}

TERSEDIA ONLINE

01 Februari 2017

\section{Pendahuluan}

Air merupakan sumber daya alam yang melimpah, dimana air dapat ditemukan disetiap tempat di permukaan bumi, air juga merupakan sumber daya alam yang sangat penting dan dibutuhkan oleh setiap mahluk hidup. Bagi manusia kebutuhan air amatlah mutlak, hampir semua aktifitas manusia memerlukan air, bagi manusia keperluan air sangatlah penting untuk keperluan hidup seharihari seperti makan, minum, mandi dan lainnya (Sapparudin, 2010). Pemanfaatan air dalam berbagai kepentingan harus dilakukan secara bijaksana dengan memperhitungkan kepentingan generasi sekarang dan generasi mendatang. Sebagai upaya pemenuhan kebutuhan air dalam kehidupan sehari-hari, penyediaan air tanah selalu dikaitkan dengan kondisi air tanah yang sehat, murah dan tersedia dalam jumlah yang sesuai kebutuhan.

Air tanah merupakan salah satu sumber air yang dapat mengatasai permasalahan kekurangan air bersih dalam kehidupan makhluk hidup seharihari. Air tanah tersimpan dalam lapisan pembawa air yang disebut akuifer. Air yang berada pada akuifer dapat menjadi salah satu hasil air terpenting 
yang dapat mengatasi kebutuhan air di muka bumi (Sulu et al, 2015)

Usaha untuk mendapatkan susunan mengenai lapisan bumi, kita harus melakukan kegiatan penelitian bawah permukaan tanah. Melalui lapisanlapisan di bawah permukaan tanah dapat digunakan untuk mengetahui keberadaan air (akuifer). Air tanah tidak dapat secara langsung diamati melalui permukaan bumi, penelitian permukaan tanah merupakan awal penelitian yang cukup penting, paling tidak dapat memberikan suatu gambaran mengenai lokasi keberadaan air tanah tersebut. Beberapa metode penelitian yang dapat digunakan untuk mengetahui lapisan bawah permukaan tanah diantaranya : metode geologi, metode gravitasi, metode magnit, metode seismik, dan metode geolistrik. Metode geolistrik merupakan metode yang paling banyak digunakan dan hasilnya cukup baik. Metode geolistrik ini dimaksudkan untuk memperoleh gambaran mengenai lapisan tanah di bawah permukaan dan kemungkinan terdapatnya air tanah dan mineral pada kedalaman tertentu (Loke. 1999). Metode geolistrik ini didasarkan pada kenyataan bahwa material yang berbeda akan mempunyai tahanan jenis yang berbeda apabila dialiri arus listrik. Air tanah mempunyai tahanan jenis yang lebih rendah daripada batuan mineral (Halik dan Jojoh, 2008)

Kebutuhan cadangan air yang banyak di Kampus UNSRAT, khususnya Masjid Kampus dalam jangka waktu yang panjang belum dapat dipastikan. Untuk itu perlu adanya identifikasi potensi cadangan air tanah dan persebarannya di Area Masjid Kampus. Kondisi air terutama air tanah sangat kurang. Debit dan volume air tanah yang ada disumur sangat kecil, karena air sumur yang tertampung dalam jangka waktu yang lama hanya sedikit. Untuk dapat mengetahui dimana keberadaan potensi air tanah dan persebarannya dapat dilakukan dengan survei geolistrik resistivitas. Metode geolistrik resistivitas dapat digunakan untuk mengidentifikasi keberadaan air tanah di sekitaran Masjid Kampus UNSRAT sebagai dasar acuan bagi pihak-pihak yang akan memanfaatkan sumber air tanah untuk kebutuhan air bersih.

Penelitian ini dilakukan pada 5 lintasan pengukuran. Manfaat dari penelitian ini adalah mengetahui lapisan pembawa air bawah permukaan dan memberikan informasi tentang lokasi dimana terdapat kandungan akuifer air tanah disekitar Masjid Kampus UNSRAT.

\section{Material dan Metode}

Penelitian sudah dilaksanakan di daerah sekitar Masjid Kampus Ulil Albab Universitas Sam
Ratulangi. Penelitian dilaksanakan pada bulan November 2015 sampai bulan Februari 2017.

Alat yang digunakan dalam penelitian ini adalah: Alat geolistrik resistivitymeter: Multi-Channel and Multi-Electrode Resistivity and IP Meter MAE X612-EM, Global Postioning System: Garmin, Laptop: Aspire E 14 A6, Software RES2DINV, Software Notepad dan bahan yang digunakan adalah peta Google Earth.

\section{Hasil dan Pembahasan}

\subsection{Lintasan Pengukuran}

Penelitian dengan menggunakan metode geolistrik resistivitas konfigurasi dipol-dipol yang dilakukan di Masjid Kampus Universitas Sam Ratulangi dan sekitarnya. Penelitian dilakukan pada 5 lintasan dengan menggunakan spasi elektroda yang berbeda-beda (Gambar 1). Dimana dari 5 lintasan ini sudah dapat teridentifikasi lapisan akuifer air tanah khususnya yang ada di Masjid Kampus

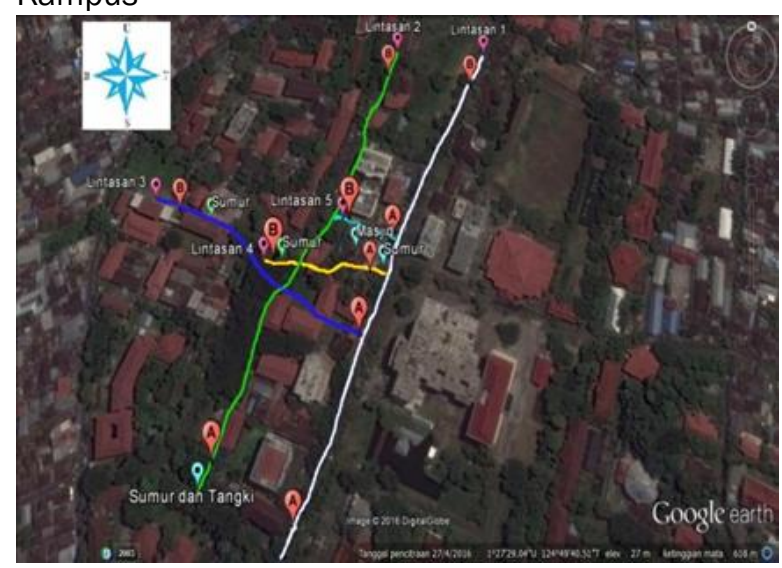

Gambar 1. Lintasan Pengukuran yang sebenarnya

\subsection{Hasil Tampang Lintang Resistivitas tiap Lintasan dengan Faktor Topografi}

\section{Lintasan 1}

Gambar 2. Menunjukkan pada daerah sumur memiliki citra warna biru tua dengan nilai resistivitas $\leq 7,62 \Omega \mathrm{m}$ yang diperkirakan terdapat akuifer air tanah yang sedikit terdapat pada kedalaman 10$15 \mathrm{~m}$ dari permukaan. Terlihat lapisan dengan citra warna biru tua pada daerah masjid bagian timur yang diduga merupakan lapisan pembawa air,akuifer ini terpisah dengan akuifer dimana terdapat sumur. Lapisan dengan nilai resitivitas tinggi berada di lapisan bawah terdapat pada elektroda ke 9-21 atau pada jarak 90-210m dari posisi awal lintasan dan terdapat juga lapisan dengan resistivitas tinggi pada elektroda 29-39 dengan nilai resistivitasnya $13189 \Omega \mathrm{m}-85064$ $\Omega m$. 


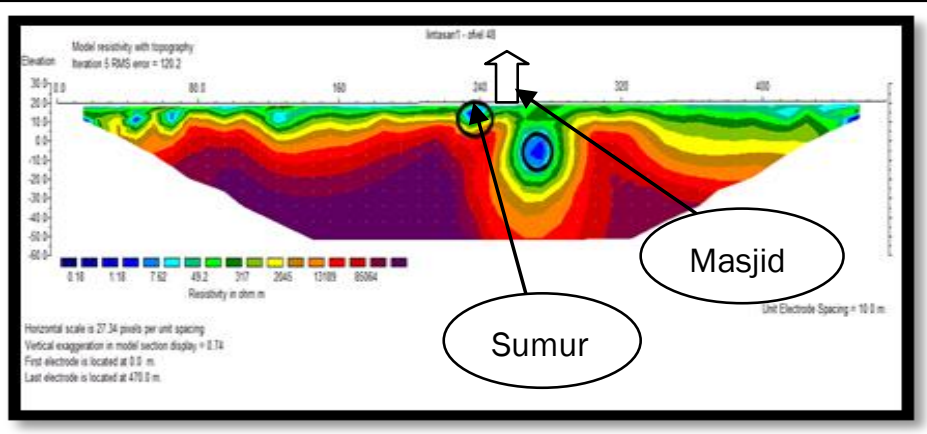

Gambar 2. Tampang lintang resistivitas lintasan 1

\section{Lintasan 2}

Gambar 3 menunjukkan pada sepanjang lintasan tidak terdapat citra warna yang menunjukkan adanya keberadaan lapisan akuifer air. Pada titik dimana tangki air berada terlihat adanya citra warna hijau muda dengan nilai resistivitas $\leq 44.7 \Omega \mathrm{m}$.

Lintasan 2 ini banyak mengandung citra warna kuning, orange, cokelat kemerah-merahan dimana citra warna ini merupakan lapisan yang keras dengan nilai resistivitasnya yang tinggi yaitu 1748 $\Omega \mathrm{m}-68270 \Omega \mathrm{m}$.

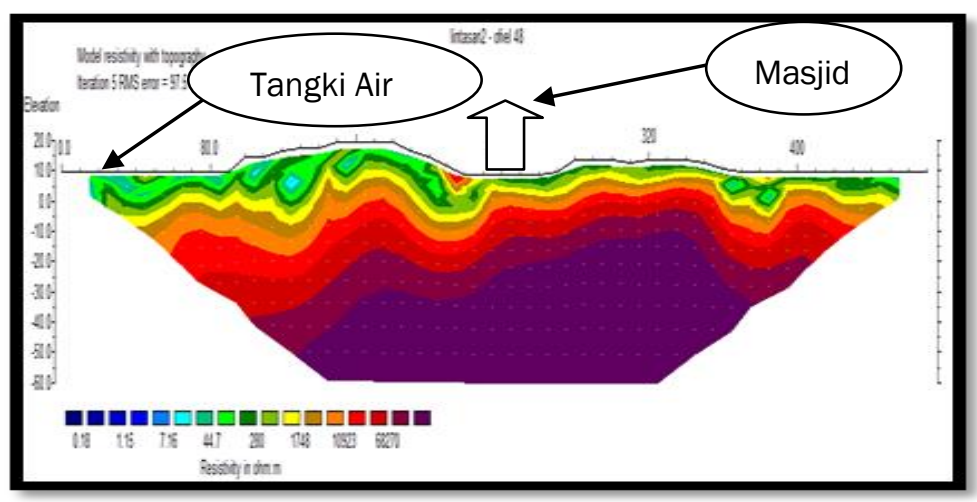

Gambar 3. Tampang lintang resistivitas lintasan 2

\section{Lintasan 3}

Gambar 4 menunjukkan lapisan dengan nilai resistivitas $\leq 7,16 \Omega \mathrm{m}$ berada pada elektroda 6-8. Sepanjang lintasan terlihat adanya citra warna hijau muda dengan nilai resistivitas $7,16 \Omega \mathrm{m}-44,7 \Omega \mathrm{m}$ berada pada kedalaman sampai 20m. Lapisan dengan citra warna kuning, cokelat yang merupakan lapisan keras dengan nilai resistivitas $1748 \Omega \mathrm{m}$ $68270 \Omega m$ berada sampai pada elektroda ke 40 dengan kedalaman sampai $30 \mathrm{~m}$ dari permukaaan.

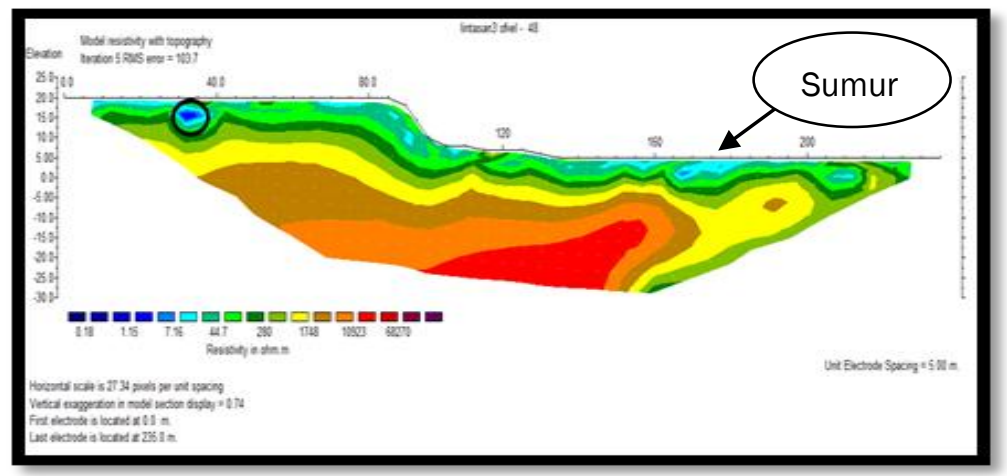

Gambar 4. Tampang lintang resistivitas lintasan 3 


\section{Lintasan 4}

Gambar 5. Menunjukkan citra warna lapisan dengan resistivitas tinggi yang besar berada pada elektroda 1-20 dengan resistivitas $1748 \Omega \mathrm{m}$ $68270 \Omega \mathrm{m}$. Ada bererapa lapisan yang mungkin lapisan dengan resistivitas yang rendah, namun hanya berada di beberapa titik elektroda dengan nilai resistivitas 7,16 $\Omega \mathrm{m}-44,7 \Omega \mathrm{m}$. Pada daerah masjid terlihat citra warna biru dengan nilai resistivitas $\leq 1.16 \Omega \mathrm{m}$ kemungkinan adanya lapisan pembawa air namun hanya sedikit

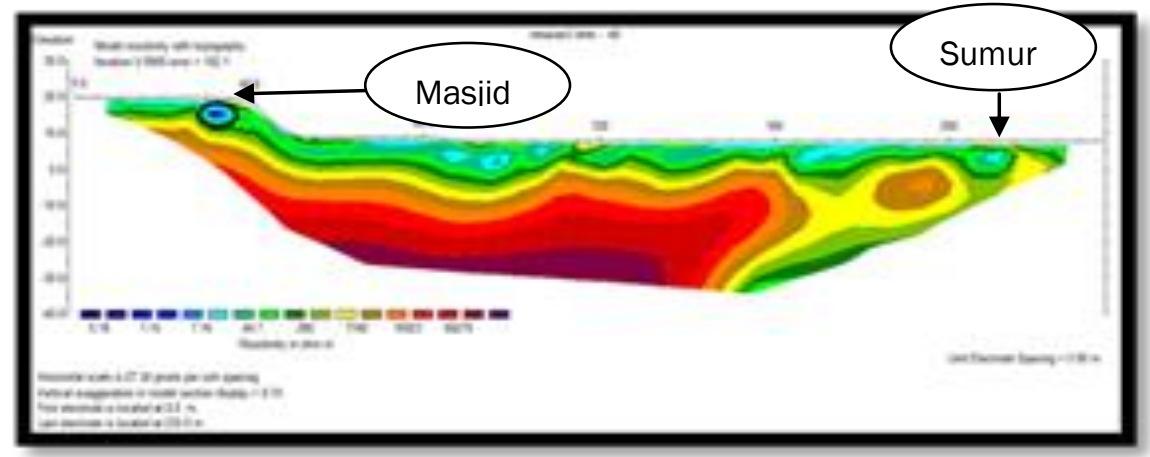

Gambar 5. Tampang lintang resistivitas lintasan 4

\section{Lintasan 5}

Gambar 6. menunjukkan posisi lapisan dengan nilai resistivitas rendah pada beberapa elektroda dengan kedalaman 20-22 m dengan nilai resistivitasnya $\leq 44.7 \Omega \mathrm{m}$. Ada lapisan dengan nilai resistitivitas tinggi yang berada pada kedalaman 2$19 \mathrm{~m}$ dengan nilai resitivitasnya $1748 \Omega \mathrm{m}-109231$ $\Omega m$.

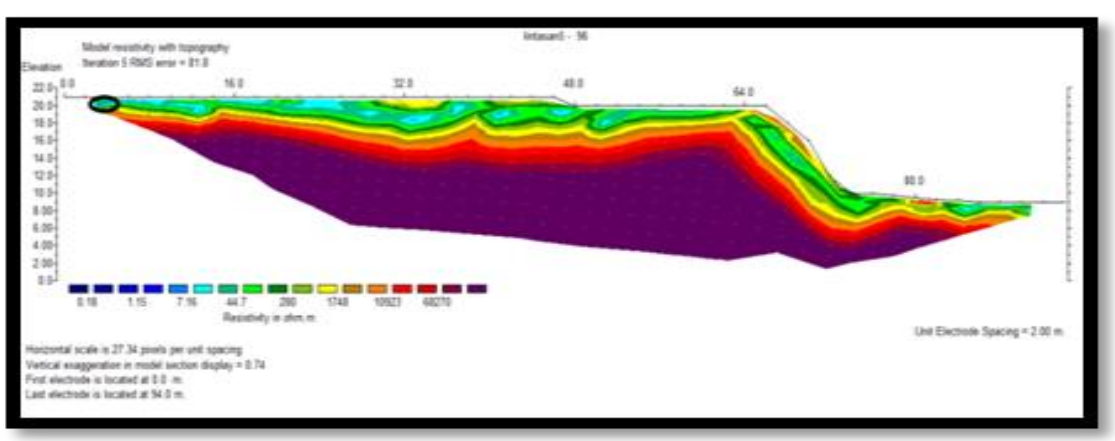

Gambar 6. Tampang lintang resistivitas lintasan 5

\section{Kesimpulan}

Telah diidentifikasi keberadaan akuifer air tanah di Masjid Kampus Universitas Sam Ratulangi dengan menggunakan metode geolistrik tahanan jenis konfigurasi dipol-dipol di daerah Masjid Kampus Universitas sam Ratulangi dan sekitarnya terdapat adanya akuifer air tanah. Teridentifikas akuifer air tanah dengan resistivitas $\rho \leq 7,16 \Omega \mathrm{m}$. Akuifer potensial terdapat pada lintasan 1 dilokasi Masjid bagian Timur dengan kedalam 0-15 m, pada lintasan 3 pada jarak $40 \mathrm{~m}$ disebelah Selatan Masjid dan lintasan 4 pada jarak $5 \mathrm{~m}$ selatan Masjid bagian Barat dengan kedalaman 14-18 m

\section{Daftar Pustaka}

Halik Gusfan dan Jojok Widodo S, 2008. Pendugaan Potensi Air Tanah Dengan Metode Geolistrik Konfigurasi Schlumberger Di Kampus Tegal
Boto Universitas Jember. Fakultas Teknik Universitas Jember

Loke, M.H., Barker, R.D. 1999. Rapid least-squares inversion of apparent resistivity pseudosections using a quasi-Newton method. Geophysical Prospecting, 44, 131152.

Sapparuddin.2010. Pemanfaatan Air Tanah Dangkal Sebagai Sumber Air Bersih Di Kampus Bumi Bahari PAlu. Jurnal SMARTek, Vol.8, No.2 : 143-152. [Jurnal]

Sulu Sweetny, As'ari dan Seni H.J Tongkukut, 2015. Pemetaan Akuifer Air Tanah Di wilayah Kampus Unsrat Manado dengan Menggunakan Metode Geolistrik Tahanan. Jurnal IImiah Sains. 